\title{
Characterization of polycyclic aromatic hydrocarbons in suspended fine particulate matter emitted from rice husk burning under different combustion temperature conditions
}

\author{
Q. Wang ${ }^{1}$, K. Kobayashi ${ }^{1}$, S. Lu ${ }^{2}$, S. Itoh ${ }^{1} \&$ D. Nakajima ${ }^{3}$ \\ ${ }^{1}$ Graduate School of Science and Engineering Saitama University, Japan \\ ${ }^{2}$ Shanghai University, China \\ ${ }^{3}$ National Institute for Environmental Studies, Japan
}

\begin{abstract}
There exists large quantities of waste rice husk and around 3 million tons is estimated as biomass waste every year in Japan. Air pollutants emitted from exhaust gases of rice husk incineration lead to environmental damage, not only because of the influence on global environment and climate, when released into the atmosphere, but also on human health due to local air pollution. Therefore, it is necessary to effectively utilize waste rice husk to reduce air pollutants. In recent years, there is an increasing demand on the utilization of unused biomass instead of fossil oil fuel in combustors for farming-greenhouses heating during the winter season. With increasing demand will increase the running costs. In general, since these combustors are small scale in their sizes, there are lack of regulations or laws (e.g. the air pollution control act and the waste disposal and public cleaning law) in operation for their air pollution control. Although the small size combustors are characterized by their simplicity of structure and the low costs, however, they emit visible black carbon so-called elemental carbon as suspended fine particulate matter due to their poor combustion performance.

In this study, we investigated the possibility of the substitution of fossil fuel by waste rice husk in laboratory model combustion experiments. We evaluated the emission behavior of harmful air pollutants emitted from rice husk combustion by measuring carbonaceous and polycyclic aromatic hydrocarbons (PAHs) in suspended fine particulate matter caused from the exhaust gases. From the analytical results we found that particulate mass concentrations reduced
\end{abstract}


substantially at high temperature combustion. The $\mathrm{PAH}_{\text {tot }}$ (total 27 species) varied in the range $72.5-876 \mathrm{ng} / \mathrm{g}$ at different combustion temperature. PAHs emissions and molecular weight increased with combustion temperature rise. We firstly reported that the six ring $\mathrm{PAHs}(\mathrm{AA}, \mathrm{DB}(\mathrm{a}, \mathrm{e}) \mathrm{F}, \mathrm{DB}(\mathrm{a}, \mathrm{l}) \mathrm{P}, \mathrm{DB}(\mathrm{a}, \mathrm{e}) \mathrm{P}, \mathrm{DB}(\mathrm{a}, \mathrm{i}) \mathrm{P}$ and $\mathrm{DB}(\mathrm{a}, \mathrm{h}) \mathrm{P})$ are discharged from biomass burning in different combustion temperatures using small size combustors. From the results of our study, it can be suggested that stable combustion performance under suitable conditions in order to control less air pollutants emitted from biomass fuel although small size combustors are still not regulated. However, it is very necessary to develop appropriate exhaust gas treatment technology for the small combustion equipment. Keywords: rice husk, rice straw, small size combustor, combustion conditions, carbonaceous composition, polycyclic aromatic hydrocarbons.

\section{Introduction}

Currently, global warming is become increasingly evident in the global climate. Combustion of fossil fuel is generally admitted as the main cause for global warming. Though, the use of fossil fuel is expected to increase in the future because of economic development and growth of population in developing countries [1], hence, the only solution is zero-emission technology, that is, to reduce all possible emissions produced by human activities to zero [2]. In order to achieve zero-emissions, it is important to apply the technologies to effectively utilize all unused biomass $[3,4]$.

Currently in Japan, the agriculture and forestry activity produce biomass residues from where a very small amount is used, and unused biomass is mostly being incinerated for disposal, due to its high cost of collection, transport, and storage and also the needs of energy that it implies. Moreover, it is required to take the urgent countermeasures for reducing the air pollution from burning and illegal incineration of waste biomass. It has estimated that only in Japan around 3 million tons of waste rice husk is considering as waste every year which are the most common agricultural waste residue biomass in the country. Additionally, since rice is the staple food and regular part of the diet for almost half of the world population, it is important to protect global warming by the effective utilization of waste rice husk and rice straw as biomass fuel. In recent years, there is an increasing demand on the utilization of unused biomass instead of usual fossil oil fuel combustion for farming-greenhouses heating during the winter season. With increasing demand of biomass fuel will also increase the cost. Therefore, biomass fuel combustors are generally made in small size and small scale [5]. The small size combustors are characterized by simplicity on their structure and low costs. However, although it was found that visible black carbon so-called elemental carbon and other air pollutants emitted due to the poor combustion performance but still there are the lack of laws and regulations [6,7]. Therefore, it is also necessary to improve existing regulations (e.g. the air pollution control act and the waste disposal and public cleaning law) and plot out new countermeasure for the effective utilization of agricultural wastes like rice husk as biomass fuel. 
In this study, the model combustion and emission behaviour of waste rice husk biomass as fuel were investigated based on the laboratory experiments. Firstly, the chemical composition of waste rice husk was analyzed to investigate its combustion characteristics. Then, suspended fine particulate matter such as $\mathrm{PM}_{2.5}$ (suspended particulate matter below $2.5 \mu \mathrm{m}$ in aerodynamic diameter) and other air pollutants emitted from the combustion of waste rice husk was measured by sampling $\mathrm{PM}_{2.5}$ and gases in the exhaust under the different combustion conditions. In the case of using a small combustion device, it is necessary to investigate the optimum temperatures for the reduction of fine particles exhausted from small size combustor using agricultural residue waste biomass by controlling burning temperatures. However, there are few reports evaluated the exhaust gas after the burning of biomass at different temperatures. So, the investigation was carried out to determine the possible use of common agricultural waste biomass like rice husk as fuel in laboratory combustion experiment. Thereby, the behaviour of $\mathrm{PM}_{2.5}$ emitted from biomass combustion under different temperature conditions were also investigated.

\section{Experimental methods}

\subsection{Composition analysis of the rice husk and straw}

In this study, the samples of agricultural waste residue biomass such as rice husk was collected in the most popular agricultural area, Nigata Prefecture of Japan, and then the proximate and ultimate analyses of rice husk samples was carried out according to the Japanese industrial standard (JIS) method of JIS-M8812 and JIS-M8813.

\subsection{Evaluation of suspended particulate matter (SPM) in exhaust gases}

\subsubsection{Air sampling method for method for exhaust gases collection}

Biomass burning is an important source of primary fine particles in the atmosphere, which can influence the regional air pollution and human health. Recently, fine particles (e.g. $\mathrm{PM}_{2.5}$ ) either emitted from biomass burning or generated by photochemical reactions are of great concern because of their effect on health and environment in Japan. For example, coarse particles of suspended particulate matter (particle sizes larger than $2 \mu \mathrm{m}$ ) are unable to enter into the respiratory tract by the nose, throat and pharynges. Therefore, we feel demand to determine fine particulates of $\mathrm{PM}_{2.5}$ emitted from combustion of waste rise husk and straw in this study.

The collection devices of exhaust gases are shown in figure 1. Air flowed into the quartz tube at the rate of $2.0 \mathrm{~L} / \mathrm{min}$. With an annular electric furnace, combustion experiments were carried out in fixed bed combustion system. Combustion temperature carried out at $500,600,700,800$ and $900^{\circ} \mathrm{C}$. A quartz boat containing sample $(0.200 \mathrm{~g})$ was put into the quartz tube. The rice husk samples were taken after separating the husk from rice. The straw samples were collected from top, middle and end portion where $3 \mathrm{~cm}$ was selected in every 
portion. A dilution sampler has been extensively used to measure fine particulates emissions from combustion system as the following procedure [8]. Combustion exhaust was diluted 20 times with a diluter (Dekati DAD-100, Tokyo Dylec Corp., Japan). In order to simulate the atmospheric conditions, gas and particles were collected using an air cooling method. However, to minimize thermophoretic and condensation losses during the air sampling, all surfaces of the devices in contact with the exhaust up to the point where the exhaust was mixed with inside diluted air. The dilution sampler were electrically heated to maintain the exhaust temperature $150^{\circ} \mathrm{C}$. Upon entering the chamber, the exhaust was further diluted and rapidly cooled for essentially ambient conditions and aging time was $20 \mathrm{~s}$. In order to evaluate the $\mathrm{PM}_{2.5}$ emissions for the combustor, exhaust $\mathrm{PM}_{2.5}$ were collected on the quartz fiber filters $(35 \mathrm{~mm} \varphi, 2500 \mathrm{Q} A T-U P$, Pallflex Prpducts Corp., Japan) using two air samplers namely $\mathrm{PM}_{2.5}$ personal sampler (Model NWPS-35HS, Sibata Scientic Technology Co. Ltd., Japan). The quartz fiber filters were precombusted at $900^{\circ} \mathrm{C}$ for $3 \mathrm{~h}$. The quartz fiber filter were used for carbonaceous analysis. Gaseous components $\left(\mathrm{CO}, \mathrm{CO}_{2}, \mathrm{O}_{2}\right.$ and $\left.\mathrm{NOx}\right)$ were also evaluated by a portable gas analyzer (Model PG-250, Horiba Co. Ltd., Japan).

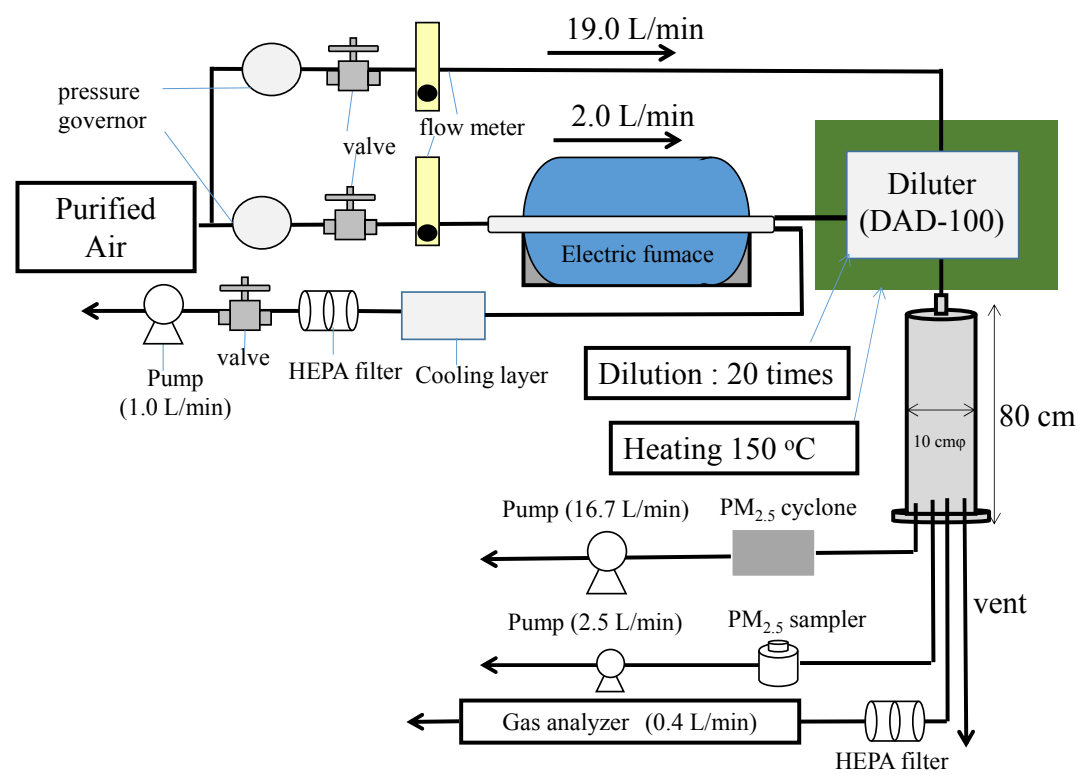

Figure 1: Air sampling setup for exhaust gases emitted from the combustor.

\subsubsection{Determination of carbonaceous compositions of $\mathrm{PM}_{2.5}$ in the exhaust gases}

Carbonaceous analysis was based on the IMPROVE method (Interagency Monitoring of Protected Visual Environment) by the thermo-optical carbon analyzer (thermo/optical carbon analyzer: Model 2001, Desert Research Institute) 
shown in table 1 . In this method, a $0.503 \mathrm{~cm}^{2}$ ( $8 \mathrm{~mm}$ diameter) punch aliquot of a sample quartz filter was heated at $120^{\circ} \mathrm{C}(\mathrm{OC} 1), 250^{\circ} \mathrm{C}(\mathrm{OC} 2), 450^{\circ} \mathrm{C}(\mathrm{OC} 3)$, and $550^{\circ} \mathrm{C}(\mathrm{OC} 4)$ in a helium atmosphere, and then at $550^{\circ} \mathrm{C}(\mathrm{EC} 1), 700^{\circ} \mathrm{C}(\mathrm{EC} 2)$, and $800^{\circ} \mathrm{C}(\mathrm{EC} 3)$ in an oxidizing atmosphere of $2 \%$ oxygen and $98 \%$ helium. The analysis was repeated two or three times for each sample for better accuracy. PM 2.5 samples were collected at the flow rate of $2.5 \mathrm{~L} \mathrm{~min}-1$ for the combustion out on each sampling with the $\mathrm{PM} 2.5$ personal sampler.

Table 1: $\quad$ Protocol of IMPROVE thermal/optical method for carbonaceous analysis.

\begin{tabular}{ccc}
\hline \multicolumn{3}{c}{ Thermal / optical method } \\
\hline Fraction & Temperture $\left({ }^{\circ} \mathrm{C}\right)$ & Atmosphere \\
\hline OC1 & 120 & \\
OC2 & 240 & $100 \% \mathrm{He}$ \\
OC3 & 450 & \\
OC4 & 550 & \\
\hline EC1 & 550 & \\
EC2 & 700 & $2 \% \mathrm{O}_{2}+98 \% \mathrm{He}$ \\
EC3 & 800 & \\
\hline
\end{tabular}

\subsubsection{Evaluation of polycyclic aromatic hydrocarbon of suspended particulate matter in the exhaust gases}

$\mathrm{PAH}_{\text {tot }}$ (total 27 species) in this study are shown as follow. Among these polycyclic aromatic hydrocarbons, 16 PAHs species controlled by priority of US Environmental Protection Agency (EPA) are Naphthalene (Nap), Acenaphthylene (Acy), Acenaphthene (Ace), Fluorene (Flu), Phenanthrene (Phe), Anthracene (Ant), Fluoranthene (Fln), Pyrene (Pry), benzo[a]anthracene (BaA), chrysene (Chy) benzo[b]fluoranthene $(\mathrm{BbF})$, benzo[k]fluoranthene $(\mathrm{BkF})$, benzo[a]pyrene (BaP) indeno[1,2,3-cd]pyrene (IcdP), benzo[g,h,i]perylene (BghiP), dibenzo[a,h]anthracene (dBahA) and 11 species of other PAHs added to the EPA in 2010 (Benzo[c]fluorine (BcFE), Cyclopenta[c,d]pyrene $(\mathrm{CP}(\mathrm{c}, \mathrm{p}) \mathrm{P}), \quad$ Benzo[j]fluoranthene $(\mathrm{BjF})$, Benz[j]aceanthrylene (BjAC), Anthanthrene (AA), Dibenzo[a,e]fluoranthene (DB(a,e)F), Dibenzo[a,1]pyrene $(\mathrm{DB}(\mathrm{a}, \mathrm{l}) \mathrm{P})$, Dibenzo[a,e]pyrene (DB(a,e)P), Dibenzo[a,i]pyrene (DB(a,i)P), Dibenzo[a,h]pyren $(\mathrm{DB}(\mathrm{a}, \mathrm{h}) \mathrm{P})$. The analytical methods for $\mathrm{PAH}_{\text {tot }}(27$ species $)$ are based on the following procedure. $\mathrm{PM}_{2.5}$ collected $47 \mathrm{~mm} \varphi$ quartz fiber filter put in a stopper spun tube. This added internal standard (deuterated PAHs of 16 species) $20 \mathrm{~L}$. This was ultrasonically extracted with $20 \mathrm{~mL}$ dichloromethane for 10 minutes, was performed three times. Extracts was concentrated in an evaporator. The solvent was added to $30 \mathrm{~mL}$ hexane, in the next place this purged $\mathrm{N}_{2}$. Silica Sep-Pak added in the order of $6 \mathrm{~mL}$ dichloromethane/hexane $(4: 1)$, hexane $(1 \mathrm{~mL})$, hexane $(9 \mathrm{~mL})$. The Sep-Pak added $1 \mathrm{~mL}$ concentrated solution, $6 \mathrm{~mL}$ dichloromethane/hexane (4:1). The solution added $100 \mathrm{~L}$ n-nonane, skipped the solvent to $0.1 \mathrm{~mL}$ with $\mathrm{N}_{2}$ purge. The solution analyzed by GC-MS. GC/MS analysis conditions is shown in table 2. 16 species PAHs concentrations were determined by internal standard method, 11 species of other PAHs asked absolute calibration method. 
Table 2: Analytical conditions condition of GC/MS analysis.

\begin{tabular}{cl}
\hline GC (Agilent 5973N) \\
Column & \multicolumn{1}{c}{ InertCap 17} \\
& $(30 \mathrm{~m} \times 0.25 \mathrm{~mm} \mathrm{ID}, 0.25 \mu \mathrm{m} \mathrm{FT})$ \\
Injector Mode & Splitless \\
& $50{ }^{\circ} \mathrm{C}(2 \mathrm{~min}$ hold $)-15^{\circ} \mathrm{C} / \mathrm{min} \rightarrow$ \\
Temperature & $185^{\circ} \mathrm{C}-8^{\circ} \mathrm{C} / \mathrm{min} \rightarrow 320^{\circ} \mathrm{C}(22 \mathrm{~min}$ hold $)$ \\
Carrier gas & $\mathrm{He} ; 1.3 \mathrm{~mL} / \mathrm{min}$ \\
Deteector system & $\mathrm{SIM} \mathrm{mode}$ \\
\hline
\end{tabular}

\section{Results and discussions}

\subsection{Measurements in the composition of waste rice husk}

The bulk composition of biomass in terms of carbon, hydrogen, and oxygen (CHO) did not differ much among different biomass sources. Typical dry weight percentages for $\mathrm{C}, \mathrm{H}$, and $\mathrm{O}$ were $30 \%$ to $60 \%, 5 \%$ to $6 \%$, and $30 \%$ to $45 \%$ respectively [9]. Table 3 shows the composition analysis of waste rice husk.

Table 3: Proximate and ultimate analysis of rice husk.

\begin{tabular}{ccccccccc}
\hline \multirow{2}{*}{ sample } & \multicolumn{4}{c}{ Proximate analysis } & & \multicolumn{3}{c}{ Ultimate analysis } \\
\cline { 2 - 5 } \cline { 7 - 8 } & $\mathrm{M}$ & VM & Ash & FC & & C & H & N \\
\hline Rice husk & 5.35 & 62.5 & 17.5 & 14.6 & & 45.1 & 5.87 & 0.518 \\
\hline
\end{tabular}

$\mathrm{M}:$ Moisture, VM : Volatile matter and FC : Fixed carbon

As the results, proximate analysis, of rice husk indicated that ash contents were high in waste rice husk, while the carbon contents were low from the ultimate analysis of waste rice husk. Since waste rice husk heating value is lower than waste rice straw based on our studies [10-11], however, waste rice husk and straw is much lower when compared to fossil fuel. Therefore, it is necessary to find the suitable combustion conditions for effective utilization as biomass fuel of waste rice husk.

\subsection{Air pollutant emitted from combustion of waste rice husk under the different combustion temperatures}

\subsubsection{Gaseous components and combustion efficiencies}

In this study, to simplify the combustion efficiency, we used the fact that $>90 \%$ of the carbon combusted in a fire was emitted in the form of $\mathrm{CO}_{2}$ and $\mathrm{CO}$, and $<10 \%$ of carbon was in species such as hydrocarbons and particulate carbon. With 
this in mind, the modified combustion efficiency (MCE) can be defined as equation (1). According to the MCE, the combustion conditions can be categorized, when $\mathrm{MCE} \geqq 0.9$ indicates smoldering combustion and $\mathrm{MCE}<0.9$ indicates flaming combustion [12].

$$
\mathrm{MCE}=\frac{\left[\mathrm{C}_{\mathrm{CO}_{2}}\right.}{[\mathrm{C}]_{\mathrm{CO}}+[{ }]_{\mathrm{CO}_{2}}}
$$

The behavior of gaseous components during waste rice husk and straw combustion under different temperatures $\left(500-1000^{\circ} \mathrm{C}\right)$ is shown in figure 2 . It was found that all of gas concentrations showed the similar behavior in two temperature ranges $500-700^{\circ} \mathrm{C}$ and $800-1000^{\circ} \mathrm{C}$.
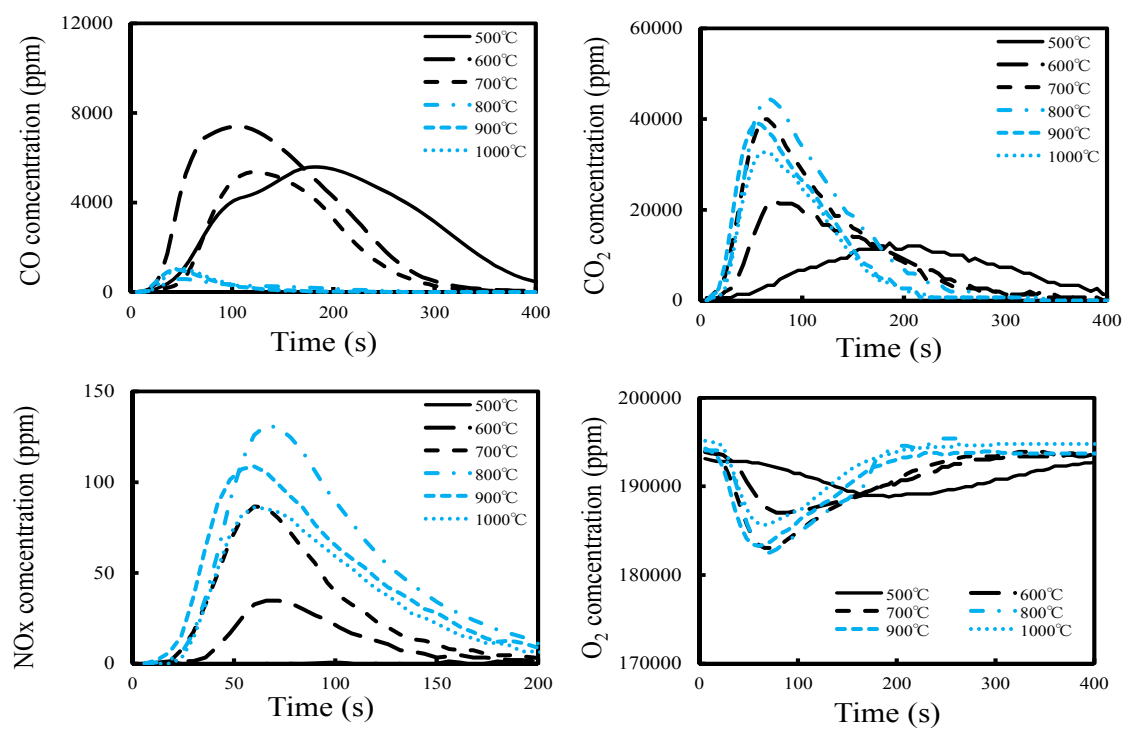

Figure 2: Gaseous components emitted from combustion of waste rice husk under the different combustion temperatures.

Figure 3 show the variation of the modified combustion efficiency (MCE) under all combustion conditions with the different temperatures. For example, as figure 3 also shown, during the temperature ranges of $700-800^{\circ} \mathrm{C}, \mathrm{CO}$ and $\mathrm{O}_{2}$ concentrations were increased under smoldering combustion conditions, and $\mathrm{NO}_{\mathrm{X}}$ and $\mathrm{CO}_{2}$ concentrations were increased under flaming combustion conditions. These results indicate that the combustion efficiencies under flaming combustion are better than under smoldering combustion. Biomass fuel is regarded as a 
renewable energy source with low $\mathrm{CO}_{2}$ emissions if produced in a sustainable manner. Under this point of view, if we use waste rice husk and straw as more effective fuel combustion, the emission of $\mathrm{CO}_{2}$ is less or not contributing to global warning.

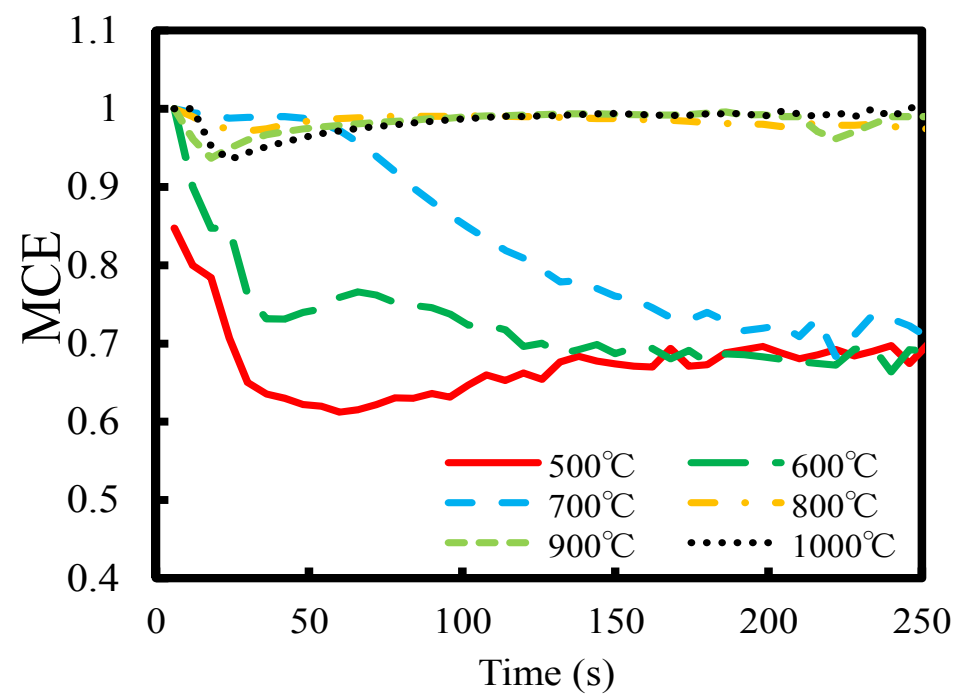

Figure 3: Gas components emitted from combustion of waste rice husk under the different combustion temperatures.

\subsubsection{Carbonaceous compositions in $\mathbf{P M}_{2.5}$}

The effect of combustion temperature on carbonaceous composition in $\mathrm{PM}_{2.5}$ was investigated. The results of carbonaceous composition analysis are shown in figure 4. OC compositions includes compounds like levoglucosan and methoxyphenol, which are generated in the thermolysis of cellulose and lignin, levoglucosan is one of the water-soluble organic substances and it can contribute to cloud condensation nuclei and influence the optical properties of aerosol. In our results, OC1 was found the highest concentrations in smoldering combustion which is mainly generated by biomass combustion at low temperatures $\left(500^{\circ} \mathrm{C}\right)$. On the other hand, in smoldering combustion EC composition was dominated by EC1 (char-EC). Under flaming combustion, OC mass concentrations were decreased significantly, and EC concentrations were dominated by EC2 (soot-EC). However, EC $(\mathrm{EC} 1+\mathrm{EC} 2)$ were emitted by smoldering combustion. Here, EC is a mostly POC, $\mathrm{POC}$ is $\mathrm{OC}(\mathrm{OC} 3)$. Therefore, as shown in figure 4, EC has not been nearly exhausted in smoldering combustion. From the results of total carbonaceous concentration $(\mathrm{OC}+\mathrm{EC})$, we observed the carbonaceous concentrations in $\mathrm{PM}_{2.5}$ under flaming combustion were 10 times lower than under smoldering combustion. 


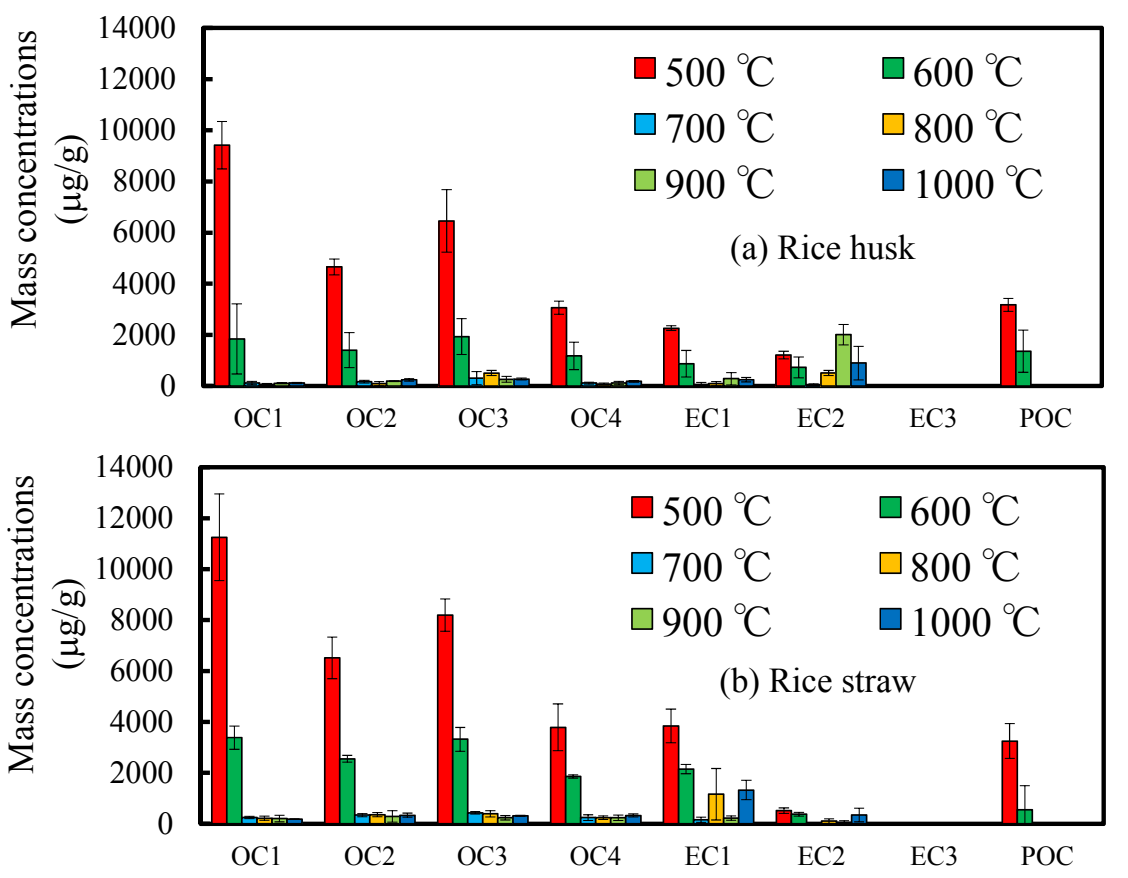

Figure 4: Carbonaceous components in $\mathrm{PM}_{2.5}$ from combustion (a) rice husk and (b) rice straw at different combustion temperatures.

\subsubsection{Polycyclic aromatic hydrocarbon (PAHs) in $\mathbf{P M}_{2.5}$}

The effect of combustion temperature on PAHs in $\mathrm{PM}_{2.5}$ was investigated. The $\mathrm{PAH}_{\text {tot }}$ (total 27 species) from combustion rice husk at different combustion temperature are shown in figure 5. And, fraction of PAHs from combustion rice husk at different combustion temperature are also shown in figure 5. The $\mathrm{PAH}_{\text {tot }}$ varied in the range $72.5-876 \mathrm{ng} / \mathrm{g}$ at different combustion temperature. The major PAHs at each temperature, at $500^{\circ} \mathrm{C}$ they were Ant and Flu. At $600^{\circ} \mathrm{C}$ they were Phe and Flu. At $700^{\circ} \mathrm{C}$ they were Pry, Fln and BaA. While at $800^{\circ} \mathrm{C}$ they were Pry, Fln and Chy. At $900^{\circ} \mathrm{C}$ they were Fln and Pry. Finally, at $1000^{\circ} \mathrm{C}$ they were Fln and Phe. PAHs emissions and molecular weight were increased when the combustion temperature rose. We firstly reported that the six ring PAHs (AA, $\mathrm{DB}(\mathrm{a}, \mathrm{e}) \mathrm{F}, \mathrm{DB}(\mathrm{a}, \mathrm{l}) \mathrm{P}, \mathrm{DB}(\mathrm{a}, \mathrm{e}) \mathrm{P}, \mathrm{DB}(\mathrm{a}, \mathrm{i}) \mathrm{P}$ and $\mathrm{DB}(\mathrm{a}, \mathrm{h}) \mathrm{P})$ were discharged from biomass burning in different combustion temperatures. Therefore, it is considered that it has become the particles highly toxic at high temperatures. At high temperatures, from the fact that low-molecular-weight PAHs between $700-900^{\circ} \mathrm{C}$ were reduced, it is estimated that larger PAHs of molecular weight has been generated by $\mathrm{H}$-abstraction $\mathrm{C}_{2} \mathrm{H}_{2}$-addition $\left(\mathrm{H}_{\mathrm{A}} \mathrm{C}_{\mathrm{A}}\right)$ mechanism or phenyladdition/cyclization (PAC) mechanism [13]. However, at $900^{\circ} \mathrm{C}$ more than combustion temperature, $\mathrm{PAH}_{\text {tot }}$ concentrations were reduced to become a soot by polymerizing [14-15]. 
Table 4: $\quad \mathrm{PAH}_{\text {tot }}(27$ species $)(\mu \mathrm{g} / \mathrm{g})$ from combustion rice husk at different combustion temperatures.

\begin{tabular}{ccccccc}
\hline \multirow{2}{*}{$\mu \mathrm{g} / \mathrm{g}$} & 500 & 600 & 700 & 800 & 900 & 1000 \\
\cline { 2 - 7 } & 50.756 & 0.0912 & 0.266 & 0.876 & 1.39 \\
\hline Total PAHs & 0.0725 & 0.750
\end{tabular}

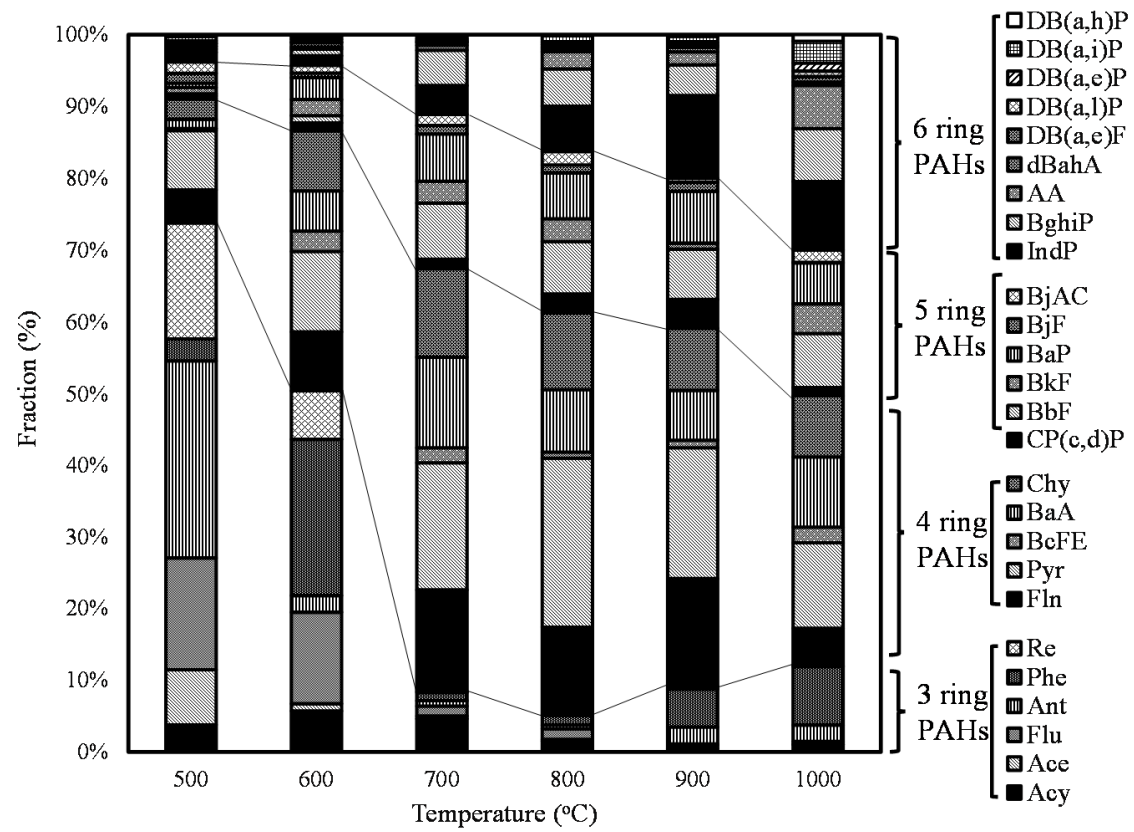

Figure 5: Fraction of PAHs from combustion rice husk at different combustion temperatures.

As mentioned above, we investigated the behavior of harmful air pollutants emitted from rice husk combustion by measuring carbonaceous and PAHs of suspended particulate matter in the exhaust gases. We will glad if the information of our study will be useful in production of small size combustors for waste rice husk or other biomass fuels.

\section{Conclusion}

In this study, we evaluated the possibility of waste rice husk substitute fossil fuel based on laboratory model combustion experiments. According to the combustion characteristics of rice husk, it is possible to use as a biomass fuel if rice husk is combusted at the temperatures above $500^{\circ} \mathrm{C}$. From analysis of gaseous compositions, it is indicated that flaming combustion $\left(800-900^{\circ} \mathrm{C}\right)$ showed better in its efficiency than smoldering combustion $\left(500-700^{\circ} \mathrm{C}\right)$. 
From the results of carbonaceous compositions, it was found that tenth part of carbonaceous particulate matter with smaller particle sizes may be only emitted under flaming combustion than under smoldering combustion. However, for strong carcinogenic and mutagenic of PAHs emissions, increased, It is necessary to the development of regulations of exhaust smoke in the combustion device. Development of appropriate exhaust gas treatment technology for small combustion equipment is also required.

\section{Acknowledgement}

Some works of this study were supported by the special funds for Basic Researches (B) (No. 22404022, FY2010-2012) of Grant-in-Aid for Scientific Research of the Japanese Ministry of Education, Culture, Sports, Science and Technology (MEXT), Japan.

\section{References}

[1] R. Saidur, E.A. Abdelaziza, A. Demirbasb, M.S. Hossaina \& S. Mekhilef, A review on biomass as a fuel for boilers, Renewable and Sustainable Energy Reviews, 15, 2262-2289, 2011.

[2] Li Dong, Shiqiu Gao \& Guangwen Xu, No reduction over Biomass Char in the Combustion Process., Energy Fuels, 24, 446-450, 2010.

[3] Lone A. Hansen, Hanne, P. Nielsen, Flemming J. Frandsen, Kim DamJohansen, Steffen Horlyck \& Asger Karlsson., Influence of deposit formation on corrosion at a straw-fired boiler., Fuel Processing Technology, 64, 189-209, 2000.

[4] E. F. Iliopoulou, E. V. Antonakou, S. A. Karakoulia, I. A. Vasalos, A. A. Lappas, \& K.S. Triantafyllidis, Catalytic conversion of biomass pyrolysis producs by mesoporous materials: Effect of steam stability and acidity of Al-MCM-41 catalysts, Chemical Engineering Journal, 134, 51-57, 2007.

[5] L. S. Johansson, C. Tullin, B. Leckner \& P. Sjovall, Particle emissions from biomass combustion in small combustors, Biomass and Bioenergy, 25, 435-446, 2003.

[6] Bernd R.T. Simoneit, Biomass burning-a review of organic tracers for smoke from incomplete combustion, Applied Geochemistry, 17, 129-162, 2002.

[7] Henrik Wiinikka \& Rikard Gebart, Experimental investigation of the particle emissions from a small-scale pellets combustor, Biomass and Bioenergy, 27, 645-652, 2004.

[8] M.-C. Oliver Chang, Judith C. Chow, John G. Watson, Philip K. Hopke, Seung-Muk Yi \& Glenn C. England, Measurement of Ultrafine Particle Size Distributions from Coal-, Oil-, and Gas-Fired Stationary Combustion Sources, Journal of the Air \& Waste Management Association, 54, 2004.

[9] A. A Khan, W. de Jong, P. J. Jansens \& H. Spliethoff, Biomass combustion in fluidized bed boilers: Potential problems and remedies, Fuel processing technology, 90, 21-50, 2009. 
[10] Q. Wang, Itoh S., Itoh K., Apaer P., Chen Q., Niida D., Mitsumura N., S. Animesh, Sekiguchi K. and Endo T., Behavior of suspended particulate matter emitted from combustion of agricultural residue biomass under different temperatures, WIT Transactions on Ecology and the Environment, Vol. 176, Energy and Sustainability IV, WIT Press, ISSN 1743-3541, 315-325 (2013) (doi: 10.2495/ESUS130271).

[11] Q. Wang, S. Itoh and S. Lu, Reduction of fine particles exhausted from small-size combustor using agricultural waste residue by controlling burning temperatures, Int. J. Sus. Dev. Plann., 9(5), 717-726 (2014) (doi: 10.2495/SDP-V9-N5-717-726).

[12] Ward D. E \& Hao W. M., Air toxic emissions from burning of biomass globally-preliminary estimates, Proceedings of Air \& Waste Management Assoc. 85th Annual Meeting \& Exhibition, 1992.

[13] Cátia Gonçalves, Célia Alves, Ana Patrícia Fernandes, Cristina Monteiro, Luís Tarelho,Margarita Evtyugina, Casimiro Pio, Organic compounds in PM2.5 emitted from fireplace and woodstove combustion of typical Portuguese wood species, Atmospheric Environment, 45, 4533-4545, 2011.

[14] E. M. Fitzpatrick, A. B. Ross, J. Bates, G. Andrews, J. M. Jones, H. Phylaktou, M. Pourkashanian and A. Williams., Emission of oxygenated species from the combustion of pine wood and its relation to soot formation, Process Safety and Environmental Protection, 85, 430-440, 2007.

[15] Fitzpatrick, E. M., Ross, A. B., Bates, J., Andrews, G., Jones, J. M., Phylaktou, H., Pourkashanian, M., Williams, A. Emission of oxygenated species from the combustion of pine wood and its relation to soot formation, Process Safety and Environmental Protection, 85, 430-440, 2007. 